\title{
Benefits and costs of the grazer-induced colony formation in Microcystis aeruginosa
}

\author{
Zhen Yang ${ }^{1,2}$, Fanxiang Kong ${ }^{1 *}$, Zhou Yang $^{3}$, Min Zhang ${ }^{1}$, Yang Yu ${ }^{1}$ and Shanqin Qian ${ }^{1,2}$ \\ ${ }^{1}$ State Key Laboratory of Lake Science Environment, Nanjing Institute of Geography and Limnology, Chinese Academy of Sciences, \\ 73 East Beijing Road, 210008 Nanjing, China \\ 2 Graduate School of the Chinese Academy of Sciences, 100039 Beijing, China \\ 3 Jiangsu Key Laboratory for Biodiversity and Biotechnology, School of Biological Sciences, Nanjing Normal University, 1 Wenyuan Road, \\ 210046 Nanjing, China
}

Received 27 April 2009; Accepted 10 July 2009

\begin{abstract}
Colonial Microcystis aeruginosa were obtained when the unicellular algae were exposed to flagellate Ochromonas sp. filtrate. To investigate the benefit of this morphological change, flagellates were added into cultures of unicellular and colonial M. aeruginosa, respectively. The clearance rates of flagellates on algae were markedly decreased when they were cultivated with induced colonial $M$. aeruginosa. This result indicated that colony formation in $M$. aeruginosa was a predator-induced defense, which could reduce predation risk from flagellate. The increased content of soluble extracellular polysaccharide (sEPS) and bound extracellular polysaccharide (bEPS) may play an important role in adhering $M$. aeruginosa cells together to form colonies. The decrease of $\Phi$ PS II and the increase of sinking rates of induced colonial M. aeruginosa showed that the costs of grazed-induced colony formation in M. aeruginosa may reflect in the photosystem II efficiency, and in the sinking rates.
\end{abstract}

Key words: Morphological plasticity / Ochromonas sp. / clearance rate / sinking rate / polysaccharide

\section{Introduction}

In aquatic systems, morphological anti-predator reaction is an important defense for plankton to reduce predation risk, which has not only been found in zooplankters (Marinone and Zaragese, 1991; Wicklow, 1997; Tollrian and Dodson, 1999), but also in algae. Hessen and van Donk (1993) discovered the grazing from Daphnia could induce colony formation in green alga Scenedesmus subspicatus. As most grazers are size selective, this enlarged-volume defense reaction could reduce their predation risk from small Daphnia magna (Hessen and van Donk, 1993) and Dahpnia cucullata (Lürling and van Donk, 1996).

According to defense theory, preys should pay some costs for their anti-grazing defense strategy (Mole, 1994; Agrawal, 1998). The grazing-induced colony formation in alga is no exception, because otherwise the defensive form would be norm (Dodson, 1989). Lürling and van Donk (2000) suggested colony formation would involve two potential costs: (1) reduced nutrient and light harvesting expressed in lower growth rates, and (2) enhanced sinking.

\footnotetext{
*Corresponding author: fxkong@niglas.ac.cn
}

However, no clear effect on growth rates have been observed in pervious studies on induced colony formation in Scenedesmus sp. (Hessen and van Donk, 1993; Lampert et al., 1994; Lürling and van Donk, 1996). Colony formation also did not lead to any decline at PS II efficiency of algae. Only the higher settling velocities of colonial population was demonstrated, which has been considered as the cost for their enlarged-volume defense reaction, because higher settling velocities would enhance their chance to sink to deeper water layers and result in reduced growth as light and temperature may be lower (Lürling and van Donk, 2000).

Microcystis aeruginosa, one of the most common species in blooms of cyanobacteria (Reynolds and Walsby, 1975; Valério et al., 2008), often forms large colonial aggregates with tens of thousands algae cell under natural conditions. But after they were isolated from the field and cultivated in axenic cultures in the laboratory for some generations, the colonial algae disaggregate and develop into unicellular algae (Reynolds et al., 1981; Bolch and Blackburn, 1996). The absence of biotic factor may be an important reason for $M$. aeruginosa remaining unicellular form in axenic cultures. A previous study in our laboratory showed that filtered lake water with 
abundant zooplankton could induce colony formation in $M$. aeruginosa, whereas $M$. aeruginosa populations in the control and the treatment of filtered lake water with few zooplankton were still strongly dominated by unicellular and paired cells and no colony was formed (Yang et al., 2005). Microcystis aeruginosa would release microcystin to resist the grazing pressure from cladocerans (Jungmann, 1992; Jang et al., 2003; Lürling, 2003), so the colony formation in $M$. aeruginosa could not be induced by cladocerans (Fulton and Paerl, 1987; Hessen and van Donk, 1993). Correspondingly, we observed colonies when $M$. aeruginosa was cultivated with the flagellate Ochromonas sp. (Yang et al., 2006). In further studies, we have demonstrated that flagellate filtrate has the ability to induce colony formation in $M$. aeruginosa, which suggested infochemicals released from flagellate fed with $M$. aeruginosa may be a trigger for colony formation in M. aeruginosa (Yang et al., 2009). Since most colonies induced by filtered flagellate culture in our previous experiments were made of few cells, we wish to determine whether these small colonies could resist the grazing of the flagellate Ochromonas sp. or not. In addition, it is worth to study if the costs of this morphological antipredator defense in $M$. aeruginosa are expressed in lower growth rates and involve effects upon their PS II efficiency and sinking rate.

\section{Materials and methods}

\section{Algae and flagellate}

The cyanobacteria Microcystis aeruginosa (Kütz.) (PCC 7806, $4.61 \pm 0.32 \mu \mathrm{m}$ ), were obtained from Institute of Hydrobiology, the Chinese Academy of Sciences, and grown in a BG-11 medium in batch culture in $250-\mathrm{mL}$ flasks (Rippka et al., 1979). The flagellate Ochromonas sp. $(8.3 \pm 0.80 \mu \mathrm{m})$ used in the experiment was isolated from the water of Lake Taihu, cultivated in culture prepared from $1000 \mathrm{~mL}$ distilled water with 20 seeds of wheat after autoclaved sterilization. The algae and flagellate cultures were grown at $25^{\circ} \mathrm{C}$ under fluorescence light at an intensity of $40 \mu \mathrm{mol}$ quanta. $\mathrm{m}^{-2} . \mathrm{s}^{-1}$ (PAR) with a light:dark period of $12: 12 \mathrm{~h}$. The algae in its late exponential growth phase were used in the experiment.

\section{Colony induction experiment}

In order to produce inducible cultures, $5 \mathrm{~mL}$ of flagellates Ochromonas sp. with a concentration at $1.4 \times 10^{5}$ individuals. $\mathrm{mL}^{-1}$ were appended into $95 \mathrm{~mL}$ of M. aeruginosa $\left(3.5 \times 10^{7}\right.$ cell. $\left.\mathrm{mL}^{-1}\right)$. After $48 \mathrm{~h}$ of grazing, the filtered cultures of flagellate were obtained by passing them through $0.10 \mu \mathrm{m}$ membrane filters (Milipore, USA). Inoculums of the exponentially growing unicellular $M$. aeruginosa $\left(1.74 \times 10^{6}\right.$ cell.mL $\left.{ }^{-1}\right)$ were transferred to three replicate $250 \mathrm{~mL}$ Erlenmeyer flasks containing medium with $20 \%$ filtered cultures of flagellates (treatments) and blank BG-11 medium (controls), respectively. Batches were incubated at $25^{\circ} \mathrm{C}$ under fluorescence light at an intensity of $40 \mu \mathrm{mol}$ quanta. $\mathrm{m}^{-2} \cdot \mathrm{s}^{-1}$ (PAR) with a light:dark period of 12:12 h for five days. Samples were daily taken and we measured the growth rates on cell number by using a hemacytometer in a microscope. The mean numbers of cells per unit and the mean proportion of different cells (unicells, two-celled, and colonies) were computed at the 5 th day of the experiment after counting at least 800 units.

\section{Defense benefit}

To determine if colony formation in $M$. aeruginosa brings defense value to to the algae or not, flagellates (40 000 individuals. $\mathrm{mL}^{-1}$ ) were added into the inducible colonial $\left(4.23 \times 10^{6}\right.$ cell. $\left.\mathrm{mL}^{-1}\right)$ and unicellular $\left(4.08 \times 10^{6}\right.$ cell. $\left.\mathrm{mL}^{-1}\right)$ M. aeruginosa cultures to observe their grazing on the induced colonial algae. Changes in the densities of algae and flagellates were determined after 12 , 24, 36, and $48 \mathrm{~h}$. The clearance rates (CR, $\mu \mathrm{L} . \mathrm{ind}^{-1} \cdot \mathrm{h}^{-1}$ ) were calculated using the equation of Peters (1984). All treatments and controls were run in triplicate under the conditions as described above.

\section{Pigment assay}

The contents of chlorophyll $a$ and phycobiliprotein in algae were determined at the 5th day after exposure to the filtrate, using the methods developed by Yan et al. (2004). For chlorophyll $a$, samples were subject to filtration with $\mathrm{GF} / \mathrm{C}$ glass microfiber filters (Whatman, UK) and extracted with $90 \%$ acetone and measured on the spectrofluorophotometer (Shimadzu, RF-5301PC, Japan) at scan speed of $60 \mathrm{~nm} \cdot \mathrm{min}^{-1}$ with a wavelength difference $\Delta \lambda=258 \mathrm{~nm}$, band pass of $5 \mathrm{~nm}$, response time of $2 \mathrm{~s}$, and low PM gain. Phycocyanin measurement was extracted using $0.05 \mathrm{M} \mathrm{pH} \mathrm{7.0} \mathrm{Tris} \mathrm{buffer} \mathrm{and} \mathrm{determined} \mathrm{on} \mathrm{the}$ spectrofluorophotometer at an excitation wavelength of $620 \mathrm{~nm}$ and an emission wavelength of $647 \mathrm{~nm}$.

\section{Polysaccharide content assay}

The content of soluble extracellular polysaccharide (sEPS), bound extracellular polysaccharide (bEPS) and intracellular polysaccharide (IPS) were quantified spectrophotometrically by the anthrone method (Herbert et al., 1971) using glucose as standard. Samples $(10 \mathrm{~mL})$ were centrifuged at $27500 \times g$ for $15 \mathrm{~min}$. The supernatants were filtrated through $0.45 \mu \mathrm{m}$ membrane filters. After dialyze of the filtrate against deionized water to remove the interference of the presence of ions in BG-11 cultures, they were used to assay the content of sEPS. The pellets were resuspended in $10 \mathrm{~mL}$ distilled water in centrifuge tubes, and the $\mathrm{pH}$ was adjusted to 10 . The centrifugation tubes were incubated in $45^{\circ} \mathrm{C}$ water for $4 \mathrm{~h}$ to extract a polysaccharide fraction that is more tightly associated 


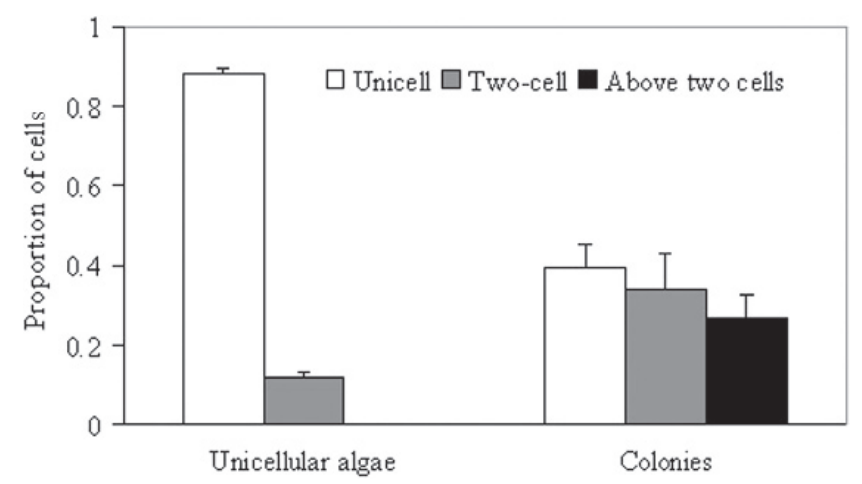

Fig. 1. Composition of the populations of unicellular and inducible colonial algae. Error bars represent $1 \mathrm{SD}(n=3)$.

with the surface of $M$. aeruginosa cells. Subsequently, the cell suspensions were centrifuged at $27500 \times g$ for $15 \mathrm{~min}$. The supernatants were filtered and dialyzed as described above and were used to assay the content of bEPS. The pellets were resuspended in $10 \mathrm{~mL}$ distilled water. After sonicating and water bath heating at $85{ }^{\circ} \mathrm{C}$ for $1 \mathrm{~h}$, they were treated with $1 \mathrm{~mL} 85 \%$ trichloracetic and centrifuged at $27500 \times g$ for $15 \mathrm{~min}$ to remove the fragments and proteins. The supernatants were filtrated and dialyzed as described above and used to assay the content of intracellular polysaccharide IPS. The polysaccharide content in each supernatant dialyzed was determined using glucose solutions for calibration.

\section{PS II efficiency and sinking rate assay}

The effective quantum yield of PS II ( $\Phi$ PS II) was determined daily using a PHYTO-PAM fluorometer (Walz, Germany) with an actinic light intensity of $364 \mu \mathrm{mol}$ quanta. $\mathrm{m}^{-2} \cdot \mathrm{s}^{-1}$ according to the equation: $\Phi$ PS II $=\left(F \mathrm{~m}^{\prime}-F\right) / F \mathrm{~m}^{\prime}$, where $F$ and $F \mathrm{~m}^{\prime}$ are the lightadapted actual and maximum fluorescence, respectively (Genty et al., 1989). The sinking rate was determined according the SETCOL procedure (Bienfang, 1981). Three $100 \mathrm{~mL}$ replicates of the controls and treatments of $M$. aeruginosa cultures after colony induction experiment were respectively poured into a $100 \mathrm{~mL}$ glass measuring cylinder and placed in the dark in a climate-controlled cabinet at $25^{\circ} \mathrm{C}$. The algal densities of the bottom $\left(C_{\mathrm{sed}}\right)$, suspension ( $C_{\text {sus }}$, sampling site up $10 \mathrm{~cm}$ above the bottom) were determined after $24 \mathrm{~h}$. The sinking rate $\left(V_{\mathrm{SED}}\right)$ of $M$. aeruginosa was calculated according to the equation:

$$
V_{\mathrm{SED}}=\left(C_{\text {sed }}-C_{\text {sus }}\right) \times C_{0}^{-1} \times h \times t^{-1}
$$

where the $C_{0}$ is the initial algal density before the sinking experiment, and the $h$ and $t$ are the height between the sampling sites and the elapsed time, respectively.

\section{Statistical analyses}

All data were presented as mean \pm SD. Differences between the unicellular and colonial algae were analyzed

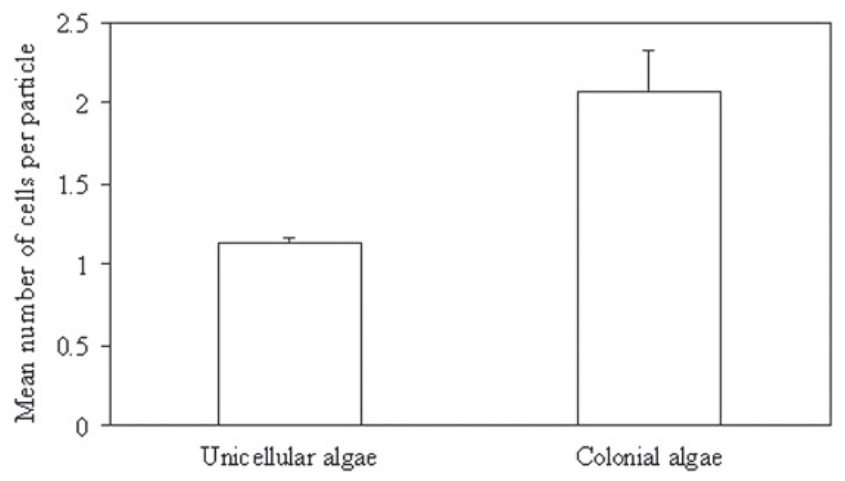

Fig. 2. Mean number of $M$. aeruginosa cells per particle in unicellular and inducible colonial algae. Error bars represent $1 \mathrm{SD}(n=3)$.

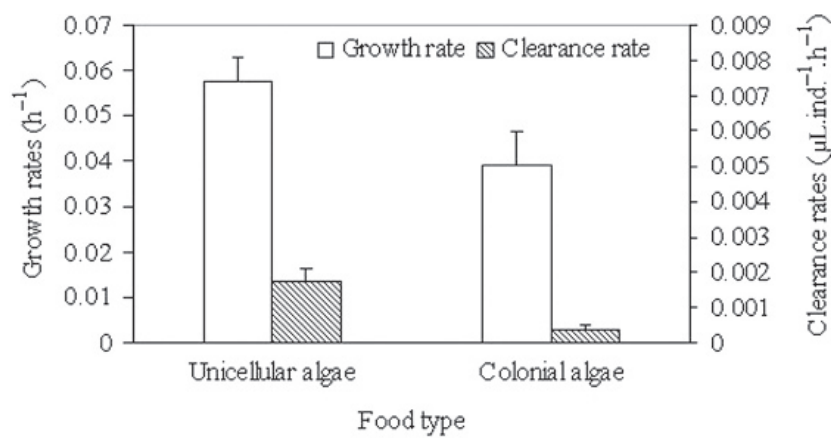

Fig. 3. Growth rates and clearance rates on M. aeruginosa of flagellates cultivated with unicellular and colonial algae in grazing experiments. Error bars represent $1 \mathrm{SD}(n=3)$.

by one-way analysis of variance (ANOVA) after testing for homoscedasticity of the data, and the level of statistical significance was set at $P<0.05$.

\section{Results}

Microcystis aeruginosa in treatments and controls expressed good growth with mean growth rates of 0.177 $( \pm 0.026) \mathrm{d}^{-1}$ and $0.17( \pm 0.019) \mathrm{d}^{-1}$, respectively. No significant difference on the algal growth rates was detected between them. After exposure to the $20 \%$ flagellates filtrate for five days, the proportion of unicells reduced to $39.6 \pm 1.65 \%$ from $88.1 \pm 1.57 \%$ and the colonies increased from 0 to $26.5 \pm 6.42 \%$ (Fig. 1). The mean number of algae cells per unit significantly increased from $1.135( \pm 0.02)$ to $2.073( \pm 0.253)\left(F_{1,4}=41.024\right.$, $P<0.05)$ (Fig. 2).

Colony formation in $M$. aeruginosa could reduce their predation risk from flagellates. The clearance rates on induced colonial $M$. aeruginosa were significantly lower $\left(F_{1,4}=33.17, P<0.05\right)$ than those on unicellular algae (Fig. 3). Meanwhile, as the size of food enlarged, the growth rates of flagellates in the induced colonial $M$. aeruginosa cultures were significantly lower $\left(F_{1,4}=\right.$ 13.39, $P<0.05)$ than those in unicellular algae cultures. 


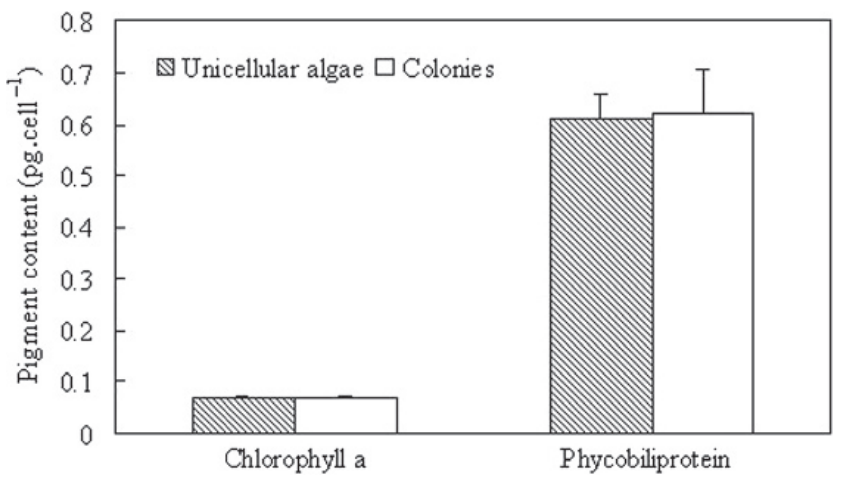

Fig. 4. Chlorophyll $a$ and phycobiliprotein content of $M$. aeruginosa in the unicellular and inducible colonial algae. Error bars represent $1 \mathrm{SD}(n=3)$.

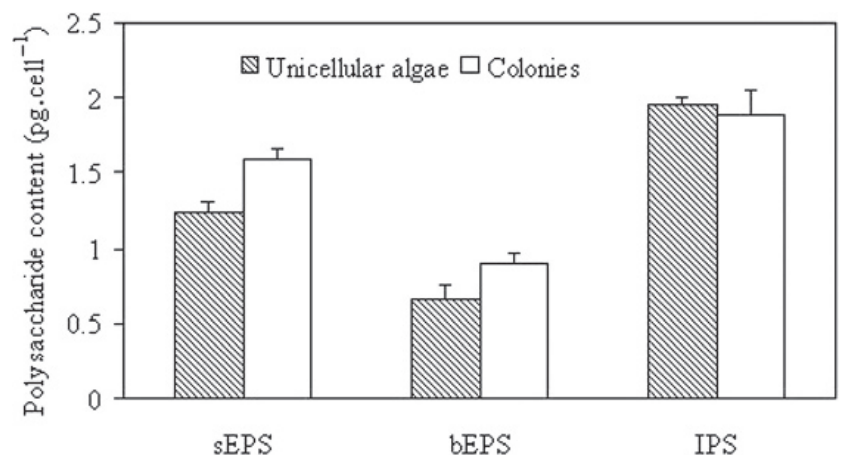

Fig. 5. Polysaccharide content of $M$. aeruginosa in the unicellular and inducible colonial algae. Error bars represent $1 \mathrm{SD}(n=3)$. sEPS, soluble extracellular polysaccharide; bEPS, bound extracellular polysaccharide; IPS, intracellular polysaccharide.

Neither chlorophyll $a$ nor phycobiliprotein showed significant difference between unicellular and colonial algae (Fig. 4). Correspondingly, the content of sEPS and bEPS in induced colonial $M$. aeruginosa were significantly higher (sEPS: $F_{1,4}=37.786, P<0.05$, bEPS: $F_{1,4}=11.25$, $P<0.05$ ) than those in unicellular algae cells (Fig. 5). However, no significantly difference in the IPS was found between induced colonial and unicellular algae.

The effective quantum yield of PS II ( $\Phi$ PS II) in both the controls and treatments increased slowly during the experiment. However, induced colonial M. aeruginosa had a lower $\Phi$ PS II than that of unicellular algae from the second day and significant difference occurred from the third day (Fig. 6). Measured sinking rates differed significantly $\left(F_{1,4}=89.75, P<0.05\right)$ between colonial and unicellular algae with mean rates of $0.008( \pm 0.004) \mathrm{m} . \mathrm{d}^{-1}$ for unicellular and $0.056( \pm 0.008) \mathrm{m}^{-\mathrm{d}^{-1}}$ for colonial M. aeruginosa.

\section{Discussion}

Infochemicals released by herbivorous zooplankton have been reported to be responsible for morphological changes in some species of algae (Hessen and van Donk, 1993; Tang, 2003; van Holthoon et al., 2003). In our study,

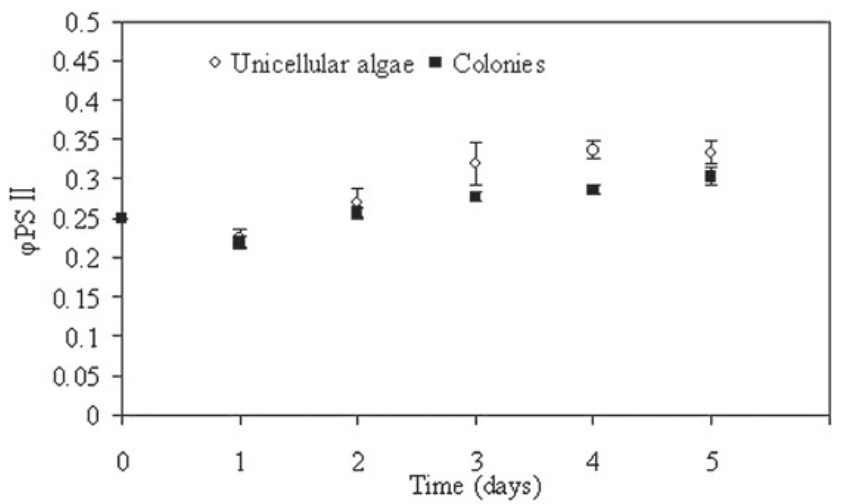

Fig. 6. Changes in the effective quantum yield of PS II ( $\Phi$ PS II) of $M$. aeruginosa in unicellular and inducible colonial algae. Error bars represent $1 \mathrm{SD}(n=3)$.

a number of unicellular algae formed colonies after exposure to $20 \%$ flagellate filtrate for five days. This suggests that infochemicals released from flagellates may trigger the morphological response of $M$. aeruginosa. Infochemicals are produced and released into the culture after the grazing of flagellates on M. aeruginosa. Microcystis aeruginosa coud thus perceive strong grazing pressure from the flagellates, and then could form colonies to resist grazing when they were exposed to the flagellate filtrate.

The colonies induced by flagellate filtrate consisted of a mixture of unicells and different colonies (two- to dozencelled). The volume of algae was enlarged after they formed colony. We found that the largest inducible colony could reach over $16 \mu \mathrm{m}$ in diameter, which led to a significant decrease in the clearance rates of flagellates because the size of prey had a significant effect on their maximum ingestion rates (Zhang and Watanabe, 1996). Releasing microcystin is a defense strategy of $M$. aeruginosa when they face the grazing pressure from cladocerans (Jungmann, 1992; Jang et al., 2003; Lürling, 2003). However, flagellates have the ability to degrade microcystin and the toxin could not serve as a growth depressor for this organism (Ou et al., 2005). Therefore, M. aeruginosa could evolve other defense strategy to have the upper hand in aquatic systems. Our results indicate that colony formation in $M$. aeruginosa could be an effective strategy to face the grazing of flagellate.

The effects of EPS on the stickiness of cells surfaces and its contribution to cell aggregation has been demonstrated in some algae (De Philippis and Vincenzini, 1998; van Rijssel et al., 2000; Pajdak-Stós et al., 2001; Thornton, 2002). In our study, the content of sEPS and bEPS in induced colonial $M$. aeruginosa were significantly higher than in unicellular algae. This result is consistent with previous ones, when $M$. aeruginosa was directly exposed to flagellates (Yang et al., 2008). The infochemicals released from the flagellates may be a main stimulator for the increased production of EPS in $M$. aeruginosa, which sticks algae cells together to form colonies.

Prey should pay some costs for colony formation as an anti-grazing defense strategy (Mole, 1994; Agrawal, 1998). 
However, the costs associated with colony formation is not clear or at least not reflected in growth rates, as no decrease in growth rates of treatments relative to controls were observed (Hessen and van Donk, 1993; Lampert et al., 1994; Lürling and van Donk, 1996). Also, we did not observed significant difference in growth rates between the two morphotypes in our study.

The good correlation between the Photosystem II electron flow and the rate of C-fixation in algae has been demonstrated (Kolber and Falkowski, 1993; Geel et al., 1997). This correlation suggests that algal growth and PS II electron flow are correlated as well (Hofstraat et al., 1994). Therefore, the change of efficiency of Photosystem II ( $\Phi$ PS II) electron transport in $M$. aeruginosa could be used as a sensitive method to estimate the costs of induced colonies in our experiments. We found that the $\Phi$ PS II of inducible colonial $M$. aeruginosa were significantly lower than those of unicellular algae. Moreover, the content of chlorophyll $a$ and phycobiliprotein between the two morphotypes were similar. This result indicates that the decreased of $\Phi$ PS II may be a metabolic cost of colonial $M$. aeruginosa in the defense strategy.

Sinking to deeper water layers could imply reduced growth as light and temperature may be lower. Thus, higher sinking rates could also be considered as a cost of grazer-induced colony formation (Reynolds, 1984; Lürling and van Donk, 2000).

Gas-vacuolate cyanobacteria such as $M$. aeruginosa have the ability to regulate their buoyancy in response to light and nutrition (Reynolds et al., 1987; Oliver, 1994; Brookes and Ganf, 2001). When cultivated in the laboratory with equal light and nutrition conditions, $M$. aeruginosa do not need to regulate buoyancy by gas vesicle to obtain more light or nutrition. Therefore, the diameter of particle becomes a main factor for the sinking rates of algal cell according the Stokes' Law. This could explain that colonial $M$. aeruginosa with an increased volume exhibit higher sinking rates than unicells in our experiments. Consequently, the cost of colony formation in $M$. aeruginosa also reflects in their higher sinking rates.

Acknowledgements. This work has been supported by State Key Fundamental Research and Development Program (2008CB418002), Natural Science Foundation of China (30670404) and the project of the Front Fields Program (CXNIGLAS200810).

\section{References}

Agrawal A.A., 1998. Algal defense, grazers, and their interactions in aquatic trophic cascades. Acta Oecol., 19, 331-337.

Bienfang P.K., 1981. SETCOL - a technically simple and reliable method for measuring phytoplankton sinking. Can. J. Fish. Aquat. Sci., 38, 1289-1294.

Bolch C.J.S. and Blackburn S.I., 1996. Isolation and purification of Australian isolates of the toxic cyanobacterium Microcystis aeruginosa Kütz. J. Appl. Phycol., 8, 5-13.
Brookes J. and Ganf G.G., 2001. Variations in the buoyancy response of Microcystis aeruginosa to nitrogen, phosphorus and light. J. Plankton Res., 23, 1399-1411.

De Philippis R. and Vincenzini M., 1998. Exocellular polysaccharides from cyanobacteria and their possible applications. FEMS Microbiol. Rev., 22, 151-175.

Dodson S.I., 1989. The ecological role of chemical stimuli for the zooplankton, predator-induced morphology in Daphnia. Oecologia, 78, 361-367.

Fulton R.S. and Paerl H.W., 1987. Toxic and inhibitory effects of the blue-green alga $M$. aeruginosa on herbivorous zooplankton. J. Plankton Res., 9, 837-855.

Geel C., Versluis W. and Snel J.F.H., 1997. Estimation of oxygen evolution by marine phytoplankton from measurement of the efficiency of photosystem II electron flow. Phot. Res., 51, $61-70$.

Genty B., Briantais J.M. and Baker N.R., 1989. The relationship between the quantum yield of photosynthesis electron transport and quenching of chlorophyll fluorescence. Biochem. Biophys. Acta, 990, 87-92.

Herbert D., Phipps P.J. and Strange R.E., 1971. Chemical analysis of microbial cells, Academic Press, London, UK, $209 \mathrm{p}$.

Hessen D.O. and van Donk E., 1993. Morphological changes in Scenedesmus induced by substances released from Daphnia. Arch. Hydrobiol., 127, 129-140.

Hofstraat J.W., Peeters J.H.C., Snel J.H.F. and Geel C., 1994. Simple determination of photosynthetic efficiency and photoinhibition of Dunaliella tertiolecta by saturating pulse fluorescence measurements. Mar. Ecol. Prog. Ser., 103, 187-196.

Jang M.H., Ha K., Joo G.J. and Takamura N., 2003. Toxin production of cyanobacteria is increased by exposure to zooplankton. Freshwater Biol., 48, 1540-1550.

Jungmann D., 1992. Toxic compounds isolated from Microcystis PCC7806 that are more active against Daphnia than 2 microcystins. Limnol. Oceanogr., 37, 1777-1793.

Kolber Z. and Falkowski P.G., 1993. Use of active fluorescence to estimate phytoplankton photosynthesis in situ. Limnol. Oceanogr., 38, 1646-1665.

Lampert W., Rothhaupt K.O. and von Elert E., 1994. Chemical induction of colony formation in a green alga (Scenedesmus acutus) by grazers (Daphnia). Limnol. Oceanogr., 39, 15431550.

Lürling M., 2003. Effects of microcystin-free and Microcystin containing strains of the cyanobacterium Microcystis aeruginosa on growth of the grazer Daphnia magna. Environ. Toxicol., 18, 202-210.

Lürling M. and van Donk E., 1996. Zooplankton-induced unicell-colony transformation in Scenedesmus acutus and its effect on growth of herbivore Daphnia. Oecologia, 108, 432-437.

Lürling M. and van Donk E., 2000. Grazer-induced colony formation in Scenedesmus: are there costs to being colonial? Oikos, 88, 111-118.

Marinone M.C. and Zaragese H.E., 1991. A field and laboratory study on factors affecting polymorphism in the rotifer Keratella tropica. Oecologia, 86, 372-377.

Mole S., 1994. Trade-offs and constraints in plant-herbivore defense theory: a life-history perspective. Oikos, 71, 3-12.

Oliver R.L., 1994. Floating and sinking in gas-vacuolate cyanobacteria. J. Phycol., 30, 161-173. 
Ou D.Y., Song L.R., Gan N.Q. and Chen W., 2005. Effects of microcystins and toxin degradation by Poterioochromonas sp. Environ. Toxicol., 20, 373-380.

Pajdak-Stós A., Fialkowska E. and Fyda J., 2001. Phormidium autumnale (Cyanobacteria) defense against three ciliate grazer species. Aquat. Microb. Ecol., 23, 237-244.

Peters R.H., 1984. Methods for the study of feeding, grazing and assimilation by zooplankton, Blackwell, Oxford, UK.

Reynolds C.S., 1984. The ecology of freshwater phytoplankton, Cambridge University Press, Cambridge, UK.

Reynolds C.S. and Walsby A.E., 1975. Water blooms. Biol. Rev., 50, 437-481.

Reynolds C.S., Jaworski G., Cmiech H. and Leedale G., 1981. On the annual cycle of the blue-green alga $M$. aeruginosa Kütz. Philos. T. R. Soc. B., 293, 419-477.

Reynolds C.S., Oliver R.L. and Walsby A.E., 1987. Cyanobacterial dominance: the role of buoyancy regulation in dynamic lake environments. N. Z. J. Mar. Freshwater Res., 21, 379-390.

Rippka R., Deruelles J., WaterburyJ., Herdman M. and Stanier R., 1979. Generic assignments, strain histories and properties of pure cultures of cyanobacteria. J. Gen. Microbiol., 111, 1-61.

Tang K.W., 2003. Grazing and colony size development in Phaeocystis globosa (Prymnesiophyceae): the role of a chemical signal. J. Plankton Res., 25, 831-842.

Thornton D.C.O., 2002. Diatom aggregation in the sea: mechanisms and ecological implications. Eur. J. Phycol., 37, 149-161.

Tollrian R. and Dodson S.I., 1999. Inducible defenses in cladacera: contraints, costs, and multipredator environments, Princeton University Press, Princeton, USA.

Valério E., Faria N., Paulino S. and Pereira P., 2008. Seasonal variation of phytoplankton and cyanobacteria composition and associated microcystins in six Portuguese freshwater reservoirs. Ann. Limnol. - Int. J. Lim., 44, 189-196. van Holthoon F.L., van Beek T.A., Lürling M., van Donk E. and De Groot A., 2003. Colony formation in Scenedesmus: a literature overview and further steps towards the chemical characterisation of the Daphnia kairomone. Hydrobiologia, 491, 241-254.

van Rijssel M., Janse I., Noordkamp D.J.B. and Gieskes W.W.C., 2000. An inventory of factors that affect polysaccharide production by Phaeocystis globosa. J. Sea Res., 43, 297-306.

Wicklow B.J., 1997. Signal-induced defensive phenotypic changes in ciliated protists: morphological and ecological implications for predator and prey. J. Eukar. Microbiol., 44, 176-188.

Yan R., Kong F.X. and Han X.B., 2004. [Analysis of the recruitment of the winter survival algae on the sediments of Lake Taihu by fluorometry]. J. Lake Sci., 16, 163-168 (in Chinese with English abstract).

Yang Z., Kong F.X., Cao H.S. and Shi X.L., 2005. Observation on colony formation of Microcystis aeruginosa induced by filtered lake water under laboratory conditions. Ann. Limnol. Int. J. Lim., 41, 169-173.

Yang Z., Kong F.X., Shi X.L. and Cao H.S., 2006. Morphological response of $M$. aeruginosa to grazing by different sorts of zooplankton. Hydrobiologia, 563, 225-230.

Yang Z., Kong F.X., Shi X.L., Xing P. and Cao H.S., 2008. Changes in the morphology and polysaccharide content of Microcystis aeruginosa (cyanobacteria) during flagellate grazing. J. Phycol., 44, 716-720.

Yang Z., Kong F.X., Zhang M., Yang Z., Yu Y. and Qian S.Q., 2009. Effect of filtered cultures of flagellate Ochromonas sp. on colony formation in Microcystis aeruginosa. Int. Rev. Hydrobiol., 94, 143-152.

Zhang X.M. and Watanabe M.M., 1996. Light and electron microscopy of grazing by Poterioochromonas malhamensis (Chrysophyceae) on a range of phytoplankton taxa. J. Phycol., 32, 37-46. 